\title{
EFEITO DO TAMANHO DE PARTÍCULAS NAS PROPRIEDADES MECÂNICAS DE LIGAS DE ZIRCÔNIO REPROCESSADAS
}

\author{
Cavalheira, E. D. ${ }^{1}$; Mendes, N. M. F. ${ }^{1}$; Casini, J. C. ${ }^{2}$; Barbosa, L. P. ${ }^{1 ;}$ Silva, S. C. ${ }^{1}$; \\ Takiishi, H. ${ }^{*}$ \\ 1 Instituto de Pesquisas Energéticas e Nucleares, IPEN, SP 05508-900, Brasil \\ 2 Instituto Federal de Educação, Ciência e Tecnologia de Rondônia, IFRO, RO 76804-124, Brasil
}

*e-mail: takiishi@ipen.br

\section{Resumo}

A etapa de usinagem para fabricação de tubos e tampões de Zircaloy-4 (Zr-4) utilizados em reatores nucleares de potência à água pressurizada (reatores PWR's) geram grandes quantidades de rejeitos deste material. Devido ao alto custo do Zr-4 faz-se necessário sua reciclagem, que é estratégico para o Brasil, evitando seu descarte para o meio ambiente. Neste trabalho, os rejeitos da usinagem do Zr-4 foram aquecidos em atmosfera de hidrogênio $(923 \mathrm{~K})$ sendo o pó resultante desta etapa peneirado em malha 200 e 325 mesh (74 e $44 \mu \mathrm{m}$ ). Nesta etapa, foram retirados os materiais que não absorvem hidrogênio proveniente da usinagem, diminuindo a contaminação final da liga Zr-4. A moagem foi realizada em moinho de alta energia, utilizando pote e esferas de zircônia para diminuir a contaminação do pó. Os experimentos foram realizados em diferentes tempos de moagem (0 a 120 min). A amostra foi prensada a $200 \mathrm{MPa}$ (prensagem isotática) e sinterizada a $1423 \mathrm{~K}$ por $10 \mathrm{~h}$. A microestrutura foi analisada por microscopia eletrônica de varredura efoi determinada a dureza Vickers. Os resultados mostraram que após 60 min de moagem o tamanho médio das partículas foi de 2,4 $\mu \mathrm{m}$, a dureza Vickers foi de $425 \mathrm{HV}$ e tamanho de grão em torno de $50 \mu \mathrm{m}$. As amostras apresentaram valores de densidade hidrostática de $99 \%$ em relação à teórica, e a microestrutura apresentou morfologia típica do Zr-4da fase a e grãos equiaxiais.

\begin{abstract}
The Zircaloy-4 (Zr-4) chips are generated in a large scale at the same machining step for producing Zr-4 tubes and end-caps used in pressurized water reactors (PWR's) nuclear reactors. Reprocessing of $\mathrm{Zr}-4$ chips is strategic for Brazil due the high cost of production and also avoids discarding the material in environment. In this work the $\mathrm{Zr}-4$ chips obtained of the machining was firstly heated to $923 \mathrm{~K}$ at high purity hydrogen atmosphere to obtain fine powder particles. This powder was sieved through 200 and 325 mesh $(<75$ and $44 \mu \mathrm{m})$. The high energy ball mill was used changing the milling times $(0-120 \mathrm{~min})$. The samples were pressed to $200 \mathrm{MPa}$ (isostactic pressing) and sintered at $1423 \mathrm{~K}$ for $10 \mathrm{~h}$. The microstructures were analyzed by scanning electron microscope (SEM) and Vickers Hardness (VH)were carried out. The results shown that after 60 min milling time mean particle size $(\phi)$ is about $2.4 \mu \mathrm{m}$ and Vickers Hardness was $425 \mathrm{HV}$ and grain size was about $50 \mu \mathrm{m}$. Hydrostatic density of this sample was $99 \%$ of theoretical and a microstructure showed typical morphology of $\mathrm{Zr}-4$ with a-phase and equiaxed grains.
\end{abstract}

Keywords (Palavras chaves): Zircaloy, Zirconium alloys, Zr tubes. 


\section{Introdução}

Os componentes estruturais utilizados como revestimento dos elementos combustíveis de reatores nucleares de potência à água pressurizada (reatores PWR's) são confeccionados em ligas de zircônio conhecidas como Zircaloy-4 (Zr-4). Na fabricação destes componentes geram-se cavacos de usinagem que não podem ser descartados ao meio ambiente, pois estas ligas são materiais estratégicos na área nuclear, têm altíssimo custo e ainda não são produzidos no Brasil em escala industrial[1,2]. O reaproveitamento de cavacos de $\mathrm{Zr}$-4 tem importâncias econômica, estratégica e ambiental[3]. Na Indústria Nuclear Brasileira (INB), os cavacos de Zr-4 ocupam grandes áreas, sendo este um dos motivos também da necessidade de reciclagem destes materiais, além da sua importância econômica.Para a obtenção de ligas à base de zircônio através de sua reciclagem, o processo de hidrogenação tem se destacado pela facilidade na obtenção de pós, que podem ser reutilizados, tanto na fabricação de novos tubos de Zr-4quanto em outros produtos [1].Das etapas necessárias para obtenção do produto final, a metalurgia do pó se faz presente, pois com ela é possível obter melhor acabamento superficial e uma melhor homogeneidade microestrutural. Outra vantagem é o formato e dimensões finais da peça próximos ao desejado [3].Neste trabalho, propõe-se o desenvolvimento do $\mathrm{Zr}$-4 obtido pelo reprocessamento dos cavacos oriundos da usinagem, pelo processo de decrepitação por hidrogênio (HD) e metalurgia do pó.

\section{Materiais e Métodos}

Os cavacos foram submetidos a uma etapa de limpeza para retirada dos óleos com água e detergente.Outros metais provenientes da usinagem foram retirados aplicando campo magnético. Após limpeza, o material foi hidrogenado em um vaso de pressão de aço inox à temperatura de $723 \mathrm{~K}$ e pressão de $\mathrm{H}_{2}$ de 0,5 MPa para hidretação do Zr-4,Após a hidretração, os materiais foram cominuídos em almofariz e peneirados em malha 200 mesh $(<74 \mu \mathrm{m})$ e 325 mesh $(<44 \mu \mathrm{m})$. Nesta etapa, os metais que não foram hidretados são retirados diminuindo a contaminação do Zr-4.Em seguida, o hidreto de zircônio foi moído em moinho planetário de alta energia, modelo Pulverisette 7 Premium Line, com vasode moagem de zircônia e esferas de Zircônia-Ítria $\left(\mathrm{ZrO}_{2}-\mathrm{Y}_{2} \mathrm{O}_{3}\right)$ com ciclo hexano, como meio de moagem. A razão de esferas para pó foi de 10:1, a rotação de 200 rpm e os tempos de moagem de 60 e $120 \mathrm{~min}$. As amostras foram prensadas isostaticamente a $200 \mathrm{MPa}$ e sinterizadas a $1423 \mathrm{~K}$ por $10 \mathrm{~h}$ em alto vácuo $\left(<10^{-4}\right.$ $\mathrm{Pa})$. O hidrogênio é retirado da amostra na etapa de sinterização, entre 573 a 923K.

Os pós foram caracterizados por espalhamento de Laser (Cilas 1064), para determinar a distribuição granulométrica. A composição química da amostra após sinterização foi determinada pela técnica de espectrometria de fluorescência de raios $X$ (espectrômetro Shimadzu, modelo EDX 720). A morfologia do pó e microestrutura da amostra foram analisadas por microscopia eletrônica de varredura (MEV) utilizando o microscópio Philips modelo XL30.

\section{Resultados e discussão}

Na Fig.1 estão mostrados: (a) os cavacos de Zircaloy após limpeza, (b) após decrepitação por hidrogênio e (c) sinterizado. A hidretação dos cavacos do Zr-4 diminui o volume do material, permitindo seu armazenamento em menores áreas, que é uma necessidade da INB. A Tab. 1 apresenta resultados da distribuição do tamanho de partículas dos pós após com inuição em almofariz de ágata<325 mesh $(<44$ $\mu \mathrm{m})$, e após moagem a 60 e 120 min.Na Fig. 2 estão mostradas as micrografias do pó: $(a)<325$ mesh e (b) após moagem de $120 \mathrm{~min}$. As partículas dos pós apresentaram a forma angular e arredondada que são favoráveis às etapas de moagem, prensagem e sinterização, diminuindo a porosidade do material final.

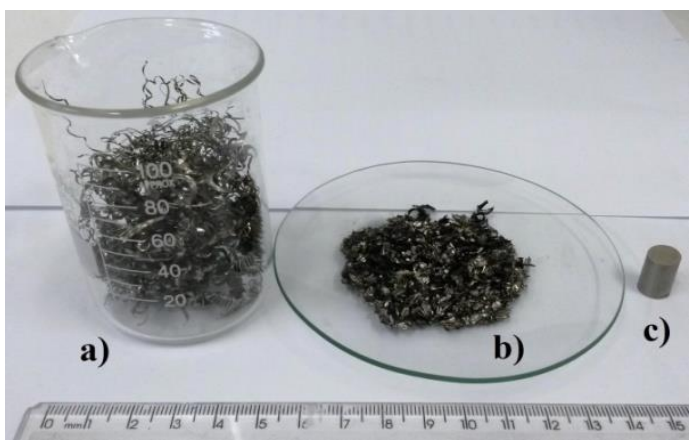

Figura 1: a) cavacos de Zr-4 como recebido após limpeza, b) pós após decrepitação por hidrogênio (HD) e c) sinterizado.

Na Tab. 2 está mostrada a análise química da amostra do pó após moagem de 60 min do Zr-4, comparando-a com sua especificação [4], onde se observa baixa 
contaminação pelo $\mathrm{Fe}$ que é um dos grandes problemas encontrados na reciclagem do $\mathrm{Zr}-4$ pelo método de fusão [3].

Tabela 1: Valores das distribuições dos tamanhos de partículas das amostras de Zircaloy <325 mesh, 60 e 120 min de moagem.

\begin{tabular}{|c|c|c|c|c|}
\hline Amostra & $\begin{array}{c}\mathrm{D} 10 \% \\
(\mu \mathrm{m})\end{array}$ & $\begin{array}{c}\mathrm{D} 50 \% \\
(\mu \mathrm{m})\end{array}$ & $\begin{array}{c}\mathrm{D} 90 \% \\
(\mu \mathrm{m})\end{array}$ & $\begin{array}{c}\text { Dmédio } \\
(\mu \mathrm{m})\end{array}$ \\
\hline $\mathrm{Zr}<325$ & 0,6 & 3,7 & 19,3 & 6,9 \\
\hline $\mathrm{Zr} \mathrm{60} \mathrm{min}$ & 0,4 & 1,8 & 5,3 & 2,4 \\
\hline $\mathrm{Zr} 120 \mathrm{~min}$ & 0,4 & 1,2 & 4,0 & 1,8 \\
\hline
\end{tabular}

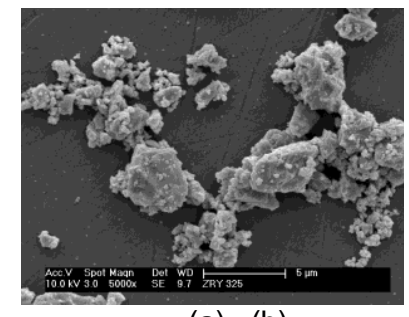

(a) (b)

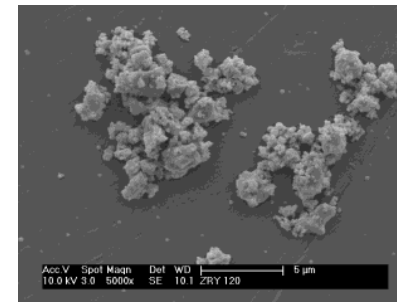

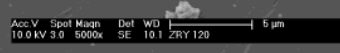

Figura2:Micrografias do pó obtidas por MEV do Zr-4 após cominuição e moagem: (a) <325 mesh e (b) após 120 min moagem.

Tabela 2: Analise química por fluorescência de raios -x da amostra Zr60.

\begin{tabular}{|c|c|c|}
\hline Elemento & Amostra Zr-60 & $\begin{array}{c}\text { Zircaloy-4 } \\
\text { Especificação[4] }\end{array}$ \\
\hline $\mathrm{Zr}$ & 98,219 & bal \\
\hline $\mathrm{Sn}$ & 1,443 & $1,2-1,7$ \\
\hline $\mathrm{Fe}$ & 0,244 & $0,18-0,24$ \\
\hline $\mathrm{Cr}$ & 0,094 & $0,07-0,13$ \\
\hline
\end{tabular}

Na Fig. 3 estão apresentadas as amostras: (a) após sinterização dos pós <44 $\mu \mathrm{m}$ e (b) 120 min de moagem e na Fig. 4 ( $a$ e b) as micrografias obtidas por MEV. As amostras após sinterização apresentaram trincas indicando que a distribuição do tamanho de partículas dos pós HD após moagem podem ter influenciado a etapa de prensagem isostática (200 MPa).

Os tamanhos de grãos, após sinterização, apresentaram diferenças entre as amostras, de 50 a $100 \mu \mathrm{m}$ para pós <325 mesh (Fig. 4 a), e menor que $50 \mu \mathrm{m}$ e após moagem a $120 \mathrm{~min}$ (Fig. 4 b).As amostras apresentaram uma microestrutura homogênea, típica do $\mathrm{Zr}$-4, com fase a e grãos equiaxiais.

A densidade hidrostática $(\rho \mathrm{H})$ e dureza Vickers (HV) das amostras após sinterização estão apresentadas na Tab. 3.

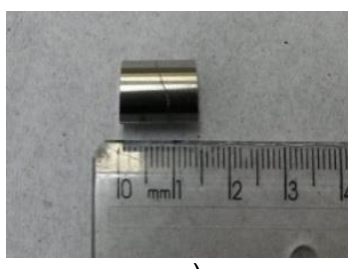

a)

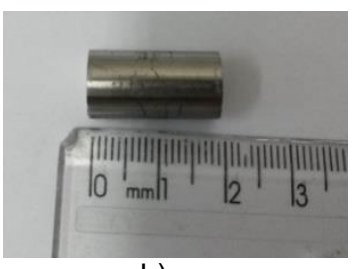

b)
Figura 3: Amostras sinterizadas obtidas com os pós: a) < 325 mesh e b) após 120 min de moagem.

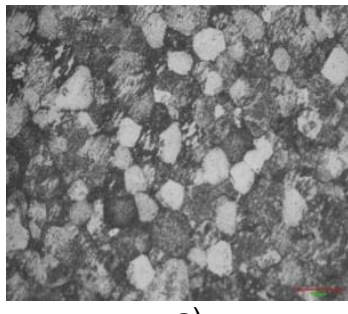

a)

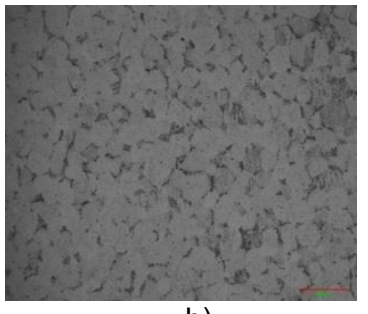

b)
Figura 4: Micrografias das amostras sinterizadas: a) pó < 325 mesh e b) após $120 \mathrm{~min}$ moagem.

Tabela 3: Densidade hidrostática das amostras sinterizadas.

\begin{tabular}{|c|c|c|}
\hline Amostra & $\rho_{\mathrm{H}}\left(\mathrm{g} \cdot \mathrm{cm}^{-3}\right)$ & Dureza $(\mathrm{HV})$ \\
\hline $\mathrm{Zr}<325$ & 6,54 & 375 \\
\hline $\mathrm{Zr} \mathrm{60} \mathrm{min}$ & 6,51 & 425 \\
\hline $\mathrm{Zr} 120 \mathrm{~min}$ & 6,46 & 440 \\
\hline
\end{tabular}

Com a diminuição do tamanho de partículas após moagem observou-se que houve decréscimo da densidade hidrostática, provavelmente devido ao aumento da porosidade nas amostras sinterizadas. Em contrapartida há um aumento da dureza Vickers com o tempo de moagem decorrente da diminuição do tamanho de grão.

\section{Conclusões}

O processo de HD e metalurgia do pó mostrou-se eficiente no reprocessamento do cavaco de $\mathrm{Zr}$ 4resultante da usinagem deste material, utilizados em reatores PWR's.A amostra após 120 min de moagem apresentou melhor dureza (440 HV).

\section{Agradecimentos}

Os autores agradecem à CNEN pelo suporte financeiro e ao IPEN-CNEN/SP pela infraestrutura.

\section{Referências}

[1] PARKISON, A. J. AND MCDEAVITT, S. M. Metal. Mat. Trans., v. 42A, p. 192-200, V. 42 A, 2011.

[2] KRISHNAN, R. and ASUNDI, M.K.Zirconium Alloys in nuclear technology. Proceedings Indian Academy Science, v. 4, n. April, p. 41-56, 1981.

[3] TAKIISHI, H.; DUVAIZEN, J. H.; SATO, I. M.; ROSSI, J. L.; L. A. T. PEREIRA, L. A. T.; MARTINEZ, L. G.Mat. Sci. Forum,Vols. 727-728, p. 356-36, 2012.

[4] BOHE, A. E.; ANDRADE GAMBOA, J. J.; LOPASSO, E. M.; PASQUEVICH, D. M. Journal of Nuclear Materials, v. 31, p. 3469-3474, 1996. 
